\title{
Para el debate La Guerra Fría recién terminó ahora
}

- Ricardo Ribera

"Después de quince años de difíciles negociaciones, finalmente llegamos a este momento histórico." Quien así se expresaba era el ministro chino de Comercio Exterior, el recién pasado 10 de noviembre, en su discurso ante la conferencia bienal de ministros de la Organización Mundial de Comercio, OMC. Puestos en pie, los ministros de los 142 países que integran el organismo aplaudieron el discurso de Shi Guang-sheng, que sellaba el ingreso de China. Poco antes, ellos mismos lo habían aprobado por unanimidad en esta reunión realizada en Qatar. La importancia de la decisión la subrayó el jefe de la delegación norteamericana, Robert Zoellick: "Creo que cuando este siglo avance y la gente mire atrás, hacia este día, llegarán a la conclusión de que, al admitir a China en la OMC, tomamos un paso decisivo para la conformación de un sistema económico y comercial global."

Las frases suenan grandilocuentes y exageradas. Típicas de los discursos en organismos internacionales. Sin embargo, en este caso se ajustan a los hechos. China, cuyo ingreso oficial en la OMC se producirá a treinta días de su admisión, o sea, el 10 de diciembre próximo, será la nación miembro número 143 , estando situada en el puesto 140 en el mundo en cuanto a PIB per cápita. Es decir, otro país pobre. Pero un gran país pobre. Con sus cerca de mil 300 millones de habitantes, China representa más del $20 \%$ de la población mundial. Dicho de otro modo: de cada cinco seres humanos, uno es chino. Se trata de un inmenso mercado potencial. Se trata, asimismo, de que la quinta parte de la humanidad se integra ahora a la economía mundial, en este sistema global del que dice Zoellick está pendiente de conformación. 
Son mil 300 millones de seres humanos capaces de aportar, con su consumo, al comercio mundial. Capaces, asimismo, de dar su aporte en la producción. La importancia del coloso chino no está solamente en su tamaño. El gigante comenzó a levantarse. Y se mueve rápido. Es ya, por su envergadura, la octava potencia económica del mundo, la séptima por exportaciones y la octava en importaciones. Además, durante la última década ha crecido a un impresionante ritmo anual del $7 \%$. El resto del mundo lo hacía a un modesto $2 \%$.

Si las tendencias se mantienen, es sólo cuestión de tiempo que China aumente sus índices de productividad y consumo internos, alcance o incluso sobrepase a otras economías del mundo desarrollado. Un sistema económico mundial sin los chinos, simplemente no podría considerarse mundial. Y no lo era. Frente al mundo de libre empresa y libre comercio, de inversiones y transferencia de tecnologías asimismo libres, o sea, frente al llamado "mundo libre", estaba el "otro mundo". Era el llamado bloque de países socialistas. La ideología de la guerra fría lo caracterizó como un mundo aparte, al que los países de capitalismo desarrollado estaban enfrentados.

De ahí la expresión "Tercer Mundo" para referirse al conjunto de naciones cuyos acuciantes problemas de pobreza y falta de desarrollo económico imponían otras prioridades a la del enfrentamiento entre los dos mundos primeros. De modo tal que a la llamada confrontación Este/Oeste se superponía la contradicción Norte/Sur. Éste fue por lo menos el esquema básico de interpretación del período de la guerra fría, el que habitualmente se considera que arrancó al fin de la segunda Guerra Mundial, allá por 1947-1948, y que culminó con la caída del muro de Berlín en noviembre de 1989, o con la desintegración de la Unión Soviética, en agosto de 1991. Es lo que prominentes historiadores, analistas políticos y líderes mundiales han repetido y hemos terminado todos repitiendo.

El problema es que el esquema resulta demasiado simple. Y lo es porque la guerra fría ha sido un fenómeno sumamente complejo. Reducirlo a coordenadas bipolares suponía olvidar las varias caras de la cuestión, ver en un simple plano lo que debería representarse en forma tridimensional. Este doble tensionamiento Este-Oeste y Norte-Sur mostraba un cruce de líneas, cual si de una topografía política se tratase. Pero era un mal mapa. No ayudaba a ubicar el problema real de los países que eran simultáneamente capitalistas y pobres, o de los tercermundistas que proclamaban el socialismo.

La guerra fría fue lucha por la hegemonía mundial entre dos superpotencias. Una especie de prolongación de las dos guerras mundiales con otros protagonistas. Derrumbada la URSS se afirma que la guerra fría terminó. Pero, ¿no era también la contradicción entre el socialismo y el capitalismo? Todavía existe el socialismo, es decir ése que se ha dado en llamar "real": en Corea del Norte, Vietnam, Cuba y China. Internamente son socialistas; al menos cabe admitir que 
hay en ellos un no-capitalismo. Pero probablemente éste no sea el verdadero punto, tal como argumentaremos más adelante.

Dado que la guerra fría fue, en parte, guerra ideológica y no únicamente competencia hegemónica, convendría corregir la fecha de su inicio. Sus antecedentes y fundamento arrancan al triunfar la primera de las revoluciones inspiradas en el ideario socialista. Su arranque sería la revolución de octubre -noviembre de 1917, según la posterior corrección hecha al calendario gregoriano--. La Rusia revolucionaria fue, de hecho, invadida, al acabar la primera guerra mundial por una coalición de países que pretendía revertir la revolución rusa. Fracasada como inicio de una revolución mundial —que es lo que había previsto Marx y que nunca se produjo-, a sus dirigentes no les tocó de otra que defender su proceso y ajustar la teoría. En esa nación relativamente atrasada se abrió paso la idea del "socialismo en un solo país", aberración de la teoría marxista, pero fórmula realista de defensa de esta primera conquista histórica del proletariado.

Acosada por todas las potencias de capitalismo desarrollado, la supervivencia forzó una estrategia económica autárquica. Sin verdadera propiedad social, sino propiedad estatal dado que la defensa nacional se constituía en prioridad, no era eso socialismo. Tampoco capitalismo: no había burguesía ni propiedad privada ni plusvalía. Era otra cosa. Lenin lo definió como "capitalismo de Estado". Lo imaginó como la vía para avanzar, muy lentamente, en la construcción de condiciones para el socialismo. Habría pequeña propiedad y mercado en pequeño, localmente, mientras el país se industrializaba o se producía la tan esperada revolución mundial o, por lo menos, revolución en alguno de los países de mayor desarrollo. Era la nueva política económica, conocida como la NEP.

Stalin prosiguió a su manera, o sea, brutalmente, el camino iniciado por Lenin. Sustituyó el modelo de economía mixta de la NEP por industrialización acelerada y colectivización forzosa. No quiso esperar a que la implacable lógica de la economía reintegrase la URSS a los lazos que la economía mundial iba entretejiendo. Conservador, prefirió seguir en el terreno ya conocido: el aislamiento. Al término de la segunda guerra mundial, con la URSS en el bando vencedor y aliada con las principales potencias económicas, la historia le daría la oportunidad de vincular a su país a la economía mundial. Pero Stalin prefirió recrear la política imperial de los zares e impulsó con los países que había liberado el Ejército Rojo una autarquía ampliada. Fue el invento del COMECON, la comunidad económica de los países socialistas. Era la base económica para la alianza militar del Pacto de Varsovia.

Así, Stalin configuró con los países de Europa del Este, a los que sometió a las necesidades de la economía soviética, un bloque político-militar y también económico. Era un mundo a espaidas de la marcha general de la historia económica de la humanidad, del desarrollo tecnológico y comercial global. Este experimento hecho a nombre del "socialismo científico" era en realidad una utopía 
sin fundamento. Fue derribada por las revoluciones democráticas de Europa oriental tras la caída del muro de Berlín. No era posible a la altura del siglo XX construir un mundo paralelo, aislado del avance histórico global, marginado del mundo real. El único modo de escapar a la mundialización sería irse a Marte o a Venus. En el planeta Tierra, el mundo es éste que viene globalizándose, al menos desde hace cinco siglos, éste que tiende a ser cada vez más un solo mundo.

Este artificio del segundo mundo no pudo mantenerse unido. Primero se salió Yugoslavia y más tarde la revolución china lo rompió. La Rusia soviética no podía absorber a la inmensa China. Nunca nadie ha podido. Mao se desmarcó de la pretensión soviética de sujetar a Pekín bajo su hegernonía. Empezó el distanciamiento con la desestalinización que emprendió Jruschov en 1956. Pronto tomaría el cariz de una virulenta disputa. Alzando la bandera del antiimperialismo, Mao acusó a la URSS de social-imperialista, colocándola en igual plano que el imperialismo yanqui. El maoísmo penetró las sociedades capitalistas desarrolladas con grupúsculos opuestos a los partidos comunistas prosoviéticos, tildados de revisionistas. China fracasó en su intento por arrebatarle el control del bloque socialista a la URSS: sólo la atrasada Albania la siguió mientras Corea del Norte, fronteriza con las dos potencias, optó por la neutralidad. Pero tuvo éxito en disputarle la influencia sobre los movimientos de liberación y las guerrillas revolucionarias del Tercer Mundo.

De tal modo, la guerra fría realmente se jugó a tres bandas. La guerra de Vietnam fue la prueba de fuego, con ambas potencias socialistas buscando atraerse al partido de Ho Chi-Minh, al tiempo que contribuían a la derrota estadounidense. Concluyó esa guerra con el inesperado acercamiento entre Washington y Pekín. Tras largas luchas en China se impuso, después de la muerte de Mao, una conducción más realista. Emprendió una línea bastante similar al planteamiento de la NEP leninista: abrirse a la inversión y la tecnología mundial, fomentar el comercio con el exterior al tiempo que flexibilizar el mercado local y permitir la pequeña propiedad privada, combinada con la gran propiedad estatal.

La gradual vinculación china a la economía mundial modifica pero no necesariamente sacrifica su socialismo. Es asunto interno. Desde la perspectiva global resulta indiferente qué tipo de organización social tenga intemamente cada una de las regiones o territorios de los Estados nacionales. Es su vinculación con el sistema mundial lo que cuenta. En lo nacional pueden regir estructuras económicas inspiradas en el socialismo o en el capitalismo, modelos de democracia o alguna variante autoritaria, constitución política monárquica o republicana, parlamentaria o dictatorial. Globalmente, no importa. Lo que ahora ha desaparecido es un modelo que a nombre del socialismo quería ser la alternativa para "salirse" del sistema mundial, hoy por hoy bajo hegemonía capitalista. Lo que a cualquier país que optase por el "campo socialista" se le ofrecía era la posibilidad de cambiar de mundo - y no sólo de bando- y pasarse a ese otro mundo 
alternativo que se gestó, en contra de las leyes del desarrollo histórico y de la evolución económica general de la humanidad.

Esto es lo que ahora termina. Salir de la economía mundial era salirse de la historia. La opción socialista seguirá siendo opción. Pero ya no la es aquélla falsa de la salida. Cualquier cambio del sistema se va a dar "desde dentro", ya no desde fuera. Porque no hay, estrictamente hablando, un "fuera" al que pueda irse. Le ha tocado a Cuba aprenderlo. Lo han comprendido asimismo Vietnam, Corea y también China. La guerra fría, por tanto, ha concluido. En noviembre de 2001, 84 años después de aquel otro noviembre, el de 1917

Los marxistas están con ello obligados a retornar a Marx. O a Bernstein, si así lo prefieren. $O$ en forma revolucionaria, o en la otra -pacífica, evolutiva y gradual, que fue planteada prematuramente por el teórico socialdemócrata-. En ambos casos, el pensamiento del siglo XIX resulta más adecuado y actual que las fórmulas que el agitado siglo XX nos heredó.

Urge la transformación del sistema vigente que domina en el mundo y que provoca efectos contrapuestos de progreso y de regresión, de civilización y de barbarie. El debate por los modelos posibles en el seno de un sistema que es único y la discusión por formas posibles de regulación y control del mismo probablemente absorberán los esfuerzos de la actual época. En un diferente marco al que imponía la guerra fría. Es un cambio de escenario. La obra sigue en el gran teatro del mundo. Falta ver si en forma más amable y placentera, al modo de la comedia griega, o si la nueva escena mantiene las viejas claves del drama. Es lo que determinará qué tanto de nuevo trae el nuevo siglo y qué tanto de continuidad. 